\title{
Structural, Conductivity, and Dielectric Properties of Nickel Oxide and Copper (Cu) or Chromium (Cr) Doped Nickel Oxide Nanoparticles
}

\section{Ali Bashal}

Taibah University

Tarob A Abdel Baset ( $\nabla$ taa03@fayoum.edu.eg )

Fayoum University https://orcid.org/0000-0002-7636-5861

\section{Mostafa Abboudi}

Taibah University

\section{Hamza Qasem}

Taibah University

\section{Fahd Al-Wadaani}

Taibah University

\section{Research Article}

Keywords: NiO Nanoparticles, $\mathrm{Cr}$ doped NiO, Cu doped NiO, Ac Conductivity, Dielectric Properties

Posted Date: April 13th, 2021

DOI: https://doi.org/10.21203/rs.3.rs-415150/v1

License: (9) This work is licensed under a Creative Commons Attribution 4.0 International License. Read Full License 


\section{Structural, Conductivity, and Dielectric Properties of Nickel Oxide and Copper (Cu) or Chromium (Cr) Doped Nickel Oxide Nanoparticles}

Ali H. Bashal ${ }^{1}$, T.A. Abdel-Baset ${ }^{2,3^{*}}$, Mostafa Abboudi ${ }^{1}$, Hamza A. Qasem ${ }^{1}$, Fahd AlWadaani $^{1}$

${ }^{1}$ Department of Chemistry, Faculty of Science, Taibah University,30002 Al Madinah Al Munawarah, KSA;

${ }^{2}$ Department of Physics, Faculty of Science, Fayoum University, Fayoum 63514, Egypt;

${ }^{3}$ Department of Physics, Faculty of Science, Taibah University-Yanbu branch, KSA;

*E-mail: tmohamed@taibahu.edu.sa 


\begin{abstract}
In this study, NiO NPs and doped NiO NPs were prepared in a two-step process and they were analyzed by scanning electron microscopy, transmission electron microscopy, X-ray diffraction, and nitrogen adsorption desorption. X-ray diffraction outcome clarified that all the patterns present the similar peaks that are attributed to the cubic variety of the $\mathrm{NiO}$ and all doping metals could be inserted into the $\mathrm{NiO}$ structure. TEM result showed that the NiO NPs are assembled side by side and aligned along the same direction to form small array shaped nano-agglomerates of $500 \mathrm{~nm}$ in length and 50-70 $\mathrm{nm}$ in diameter. Adsorption-desorption isotherms for $\mathrm{N}_{2}$ showed that NiO NPs represents type IV isotherms containing a hysteresis loop at relative pressure between 0.5 and 1.0. Hysteresis loop's shape was of $\mathrm{H}_{2}$ type which is characteristic of inckbottle shaped pores. It was also in the shape of solids composed by small spherical particles. The dielectric properties and electrical conductivity for these samples were also studied within the temperature range $25^{\circ} \mathrm{C}-110^{\circ} \mathrm{C}$ and within the frequency range $100 \mathrm{~Hz}$ to $0.3 \mathrm{MHz}$.
\end{abstract}

Keywords: $\mathrm{NiO}$ Nanoparticles, $\mathrm{Cr}$ doped $\mathrm{NiO}, \mathrm{Cu}$ doped $\mathrm{NiO}$, Ac Conductivity, Dielectric Properties. 
The material properties performance in developing the characteristics of reliable gas sensors is receiving a lot of attention from many scientists in the last few decades ${ }^{1}$. This is mainly because such sensors are widely used in several fields and in many applications particularly in hazardous environmental sensing applications as well as in chemical controlling, industrial monitoring, and home safety ${ }^{2}$. Well-known materials used in sensors application are semiconductors made from metal oxides. The electrical conductivity changes of these semi-conductors is a very important characteristic especially when interacting with gas molecules of the surrounding atmosphere ${ }^{2,3}$. Wide research has been conducted on the application of semiconductor materials including environmental, electronic and energy applications ${ }^{4}$. This application has contributed to the increasing importance of developing and improving the physical properties of semi-conductors. Investigations have mainly focused on nanoparticles especially their physical properties. These materials are known to be used in chemical and bio-applications ${ }^{5}$. It is worth noting that the properties of nanomaterials are different from the bulk counterpart owing to the quantum size effects $^{6,7}$. Metal oxides are one such type of nanomaterials, which are gaining significance across several sectors. Metal oxides are known for their unique chemical and physical properties which allow them to be used in a diverse range of optical and electronic applications ${ }^{8}$. Transition metal oxide, nickel Oxide (NiO) known for its novel morphologies owing to a number of spins and surface atoms. NiO demonstrates interesting optical, electronic and magnetic properties ${ }^{9,10,11,12}$. It is a p-type semiconductor, therefore $\mathrm{NiO}$ nanoparticles are considered a varied band-gap semicondoctor in the range of $3.6 \mathrm{eV}$ up to $4.0 \mathrm{eV}^{13,14}$. Its structure is rock-salt and displays a normal antiferromagnetic property with magnetic moments residing on $\mathrm{Ni}^{2+}$ ions. NiO has low electrical conductivity, at room temperature, of less than $10^{-13}$ $\mathrm{ohm}^{-1} \mathrm{~cm}^{-1}$ and is considered as a 'Mott-Hubbard Insulator ${ }^{15}$. Moreover, NiO, is an eco-friendly material for super-capacitor terminals and is cost-effective compared to noble metal ${ }^{16}$. $\mathrm{NiO}$ is also known for its low resistivity which is the reason for many researchers to investigate ${ }^{17}$. One of the methods utilized to overcome this low resistivity is doping $\mathrm{NiO}$ nanomaterials. Doping $\mathrm{NiO}$ with $(\mathrm{Cu}, \mathrm{Fe}, \mathrm{Au}$ or $\mathrm{Li})$ as alkali or transition metals will affect its structural, optical, electronic and magnetic properties. 
Consequently this will create a Diluted Magnetic Semiconductor because of spin degrees of freedom and holes content that improves its functionality in spintronic $^{9,13,18}$. Cu-doped $\mathrm{NiO}$ has been investigated by Manouchehri et al. The structure crystallinity declined tending to amorphous structure by increasing the metal dopant percentage ${ }^{19}$. $\mathrm{NiCu}$ and $\mathrm{NiCr}$ can be used in many settings including in dental clinical applications. For instance, NiCr-based alloys are recognized for their corrosion resistance in the oral environment that is why they are industrialized as a substitute to gold-based alloys. Benatti et al. demonstrated that the NiCr-based alloy grants acceptable resistance to corrosion in both in-vitro and in-vivo tests ${ }^{20,21}$. Considering all the above mentioned facts, synthesizing both doped and un-doped $\mathrm{NiO}$ was seen as crucial part of this study. A focal part of this investigation is to look at the effect of doping the $\mathrm{Cr}$ and $\mathrm{Cu}$ on $\mathrm{NiO}$ in terms of structure, $\mathrm{AC}$ conductivity and dielectric properties. The results presented in this study provide noteworthy data about the electrical properties which are essential for the practical applications of these types of nanoparticles.

\section{Experimental}

\subsection{Materials}

The chemicals, nickel nitrate $\mathrm{Ni}\left(\mathrm{NO}_{3}\right)_{2} 6 \mathrm{H}_{2} \mathrm{O}$, chromium nitrate $\mathrm{Cr}\left(\mathrm{NO}_{3}\right)_{3} 9 \mathrm{H}_{2} \mathrm{O}$, copper nitrate $\mathrm{Cu}\left(\mathrm{NO}_{3}\right)_{2} .3 \mathrm{H}_{2} \mathrm{O}$ and oxalic acid $\mathrm{H}_{2} \mathrm{C}_{2} \mathrm{O}_{4} .2 \mathrm{H}_{2} \mathrm{O}$ were obtained from Sigma Aldrich and utilized without modification

\subsubsection{Synthesis of NiO NPs and Doped NiO NPs}

The preparation of the NiO NPs was conducted in two steps. In the first step a precursor was synthesized using solid reaction by heating a well ground mixture of the oxalic acid and the nickel nitrate in the molar ration of $3 / 1$, respectively. The nitrates ions were reduced by the oxalic acid (equations 1 and 2). Consequently, the metal ions were coordinated by the oxalate anion existing in the mixture (equation 3 ). In the second step, the oxalate precursor was thermally decomposed in air at $400^{\circ} \mathrm{C}$ in a muffle furnace for 2 hours to produce the NiO NPs. 


$$
\begin{aligned}
\mathrm{NO}_{3}{ }^{-}+4 \mathrm{H}^{+}+3 \mathrm{e} & \longrightarrow \\
\mathrm{C}_{2} \mathrm{O}_{4}{ }^{2-} & \longrightarrow \mathrm{NO}+2 \mathrm{H}_{2} \mathrm{O} \\
\mathrm{C}_{2} \mathrm{O}_{4}{ }^{2-}+\mathrm{Ni}^{2+} & \longrightarrow 2 \mathrm{CO}_{2}+2 \mathrm{e}^{-} \\
& \longrightarrow \mathrm{NiC}_{2} \mathrm{O}_{4}
\end{aligned}
$$

The same process was conducted to synthesize the doped NiO NPs. The initial mixture was completed by oxalic acid, nickel nitrate and copper nitrate or chromium nitrate with a molar ratio of $3 / 0.9 / 0.1$, respectively. This suggests the formation of $\mathrm{Ni} 0.9 \mathrm{Cu} 0.1 \mathrm{O}$ noted as $\mathrm{NiO}: \mathrm{Cu}$ and $\mathrm{Ni} 0.857 \mathrm{Cr} 0.095 \square 0.0475 \mathrm{O}$ noted as $\mathrm{NiO}: \mathrm{Cr}$.

\subsection{Characterization}

To investigate the phase structure of the prepared materials, an X-ray diffractometer was used (XRD; Shimadzu 6000, Japan) CuK $\alpha$ radiation $\lambda=1.5406 \AA$ and an Ni filter. Crystallites size could be estimated from the obtained XRD patterns using Scherer formula: $\mathrm{DXRD}_{\mathrm{XR}}=0.9 \lambda / \mathrm{B} \cos \theta$ where $\lambda$ is the wavelength $1.5406 \AA$, $\mathrm{B}$ is the full width at half maximum (FWHM) and $\theta$ is the Bragg angle. The powders morphology, microstructure and composition were investigated through a transmission electron microscope (TEM: JEOL JEM 1400) and a Quanta FEG 250 scanning electron microscope equipped with an energy dispersive analyzer (SEM; Thermo Fischer Scientific, Hillsboro, OR, USA). Nitrogen adsorption-desorption isotherms were recorded on adsorption desorption analyzer (ASAP 2020, USA). From these curves, the specific surface area $\mathrm{S}$ of the powders could be found by Brunauer-Emmet-Teller (BET) technique and the particles size $\mathrm{D}_{\mathrm{BET}}$ was calculated by mean of the formula $D_{B E T}=6000 / d S$, where $d$ is the density of the powder and $S$ is its measured specific surface area.

\section{Results and Discussion}

\subsection{Samples Characterization}

\subsubsection{X-ray Diffraction}

Figure 1 displays the XRD image s of the undoped-NiO, NiO:Cu and NiO:Cr. It can be seen that all the patterns present the same peaks that are attributed to the cubic variety of the NiO. The peaks were indexed based on the JCPDS file \#47-1049 and no other peaks were observed. 
This suggests that all doping metals could be inserted into the NiO structure. The insertion of the doping element is confirmed by the change in crystallinity which is lower in the case of the doped nano-powders.

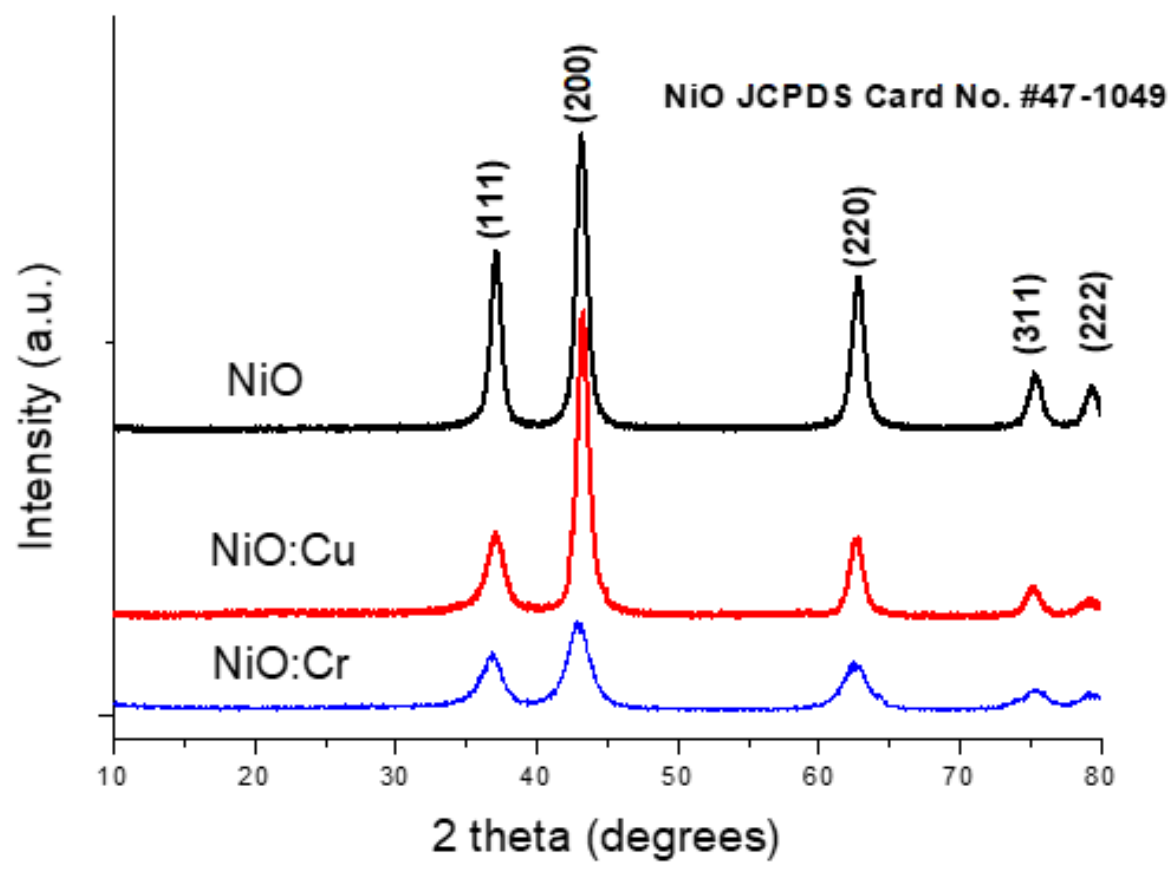

Figure 1: Compared XRD patterns of NiO NPs pure and 10\% molar doped with copper or chromium $\mathrm{NiO}: \mathrm{Cu}$ and $\mathrm{NiO}: \mathrm{Cr}$ prepared at $400^{\circ} \mathrm{C}$ in air.

Additionally, the peaks broadness increases by doping, indicating the decrease of the crystallites size that was estimated by Scherer formula. In Table 1 these calculated values will be compared to those found by calculations from the $\mathrm{N}_{2}$ adsorption desorption studies.

Table 1: Surface area, pore volume, $\mathrm{D}_{\mathrm{BET}}$ and DXRD

\begin{tabular}{ccccc}
\hline Nanomaterial & Surface area $\left(\mathrm{m}^{2} / \mathrm{g}\right)$ & Pore volume $\left(\mathrm{cm}^{3} / \mathrm{g}\right)$ & D BET $(\mathrm{nm})$ & D XRD(nm) \\
\hline $\mathrm{NiO}$ & 30.5276 & 0.106493 & 28.7 & 9.2 \\
$\mathrm{NiO}: \mathrm{Cu}$ & 66.579 & 0.273061 & 13.2 & 8.7 \\
$\mathrm{NiO}: \mathrm{Cr}$ & 179.3218 & 0.315929 & 4.9 & 4.3 \\
& & & & \\
\hline
\end{tabular}




\subsubsection{SEM and TEM Characterizations}

Representative images of the prepared materials are shown in Figure 2. On the right side of the images on Figure 2, the EDS spectra of these materials confirm the presence or the absence of the doping element by means of the characteristic X-ray emission. All the powders are formed from agglomerates where voids are observed because of the evolving gas (mainly $\mathrm{CO}_{2}$ and $\mathrm{H}_{2} \mathrm{O}$ ) formed during calcination of the oxalate precursors at $400^{\circ} \mathrm{C}$. $\mathrm{NiO}$ : $\mathrm{Cr}$ seems to be less agglomerated.
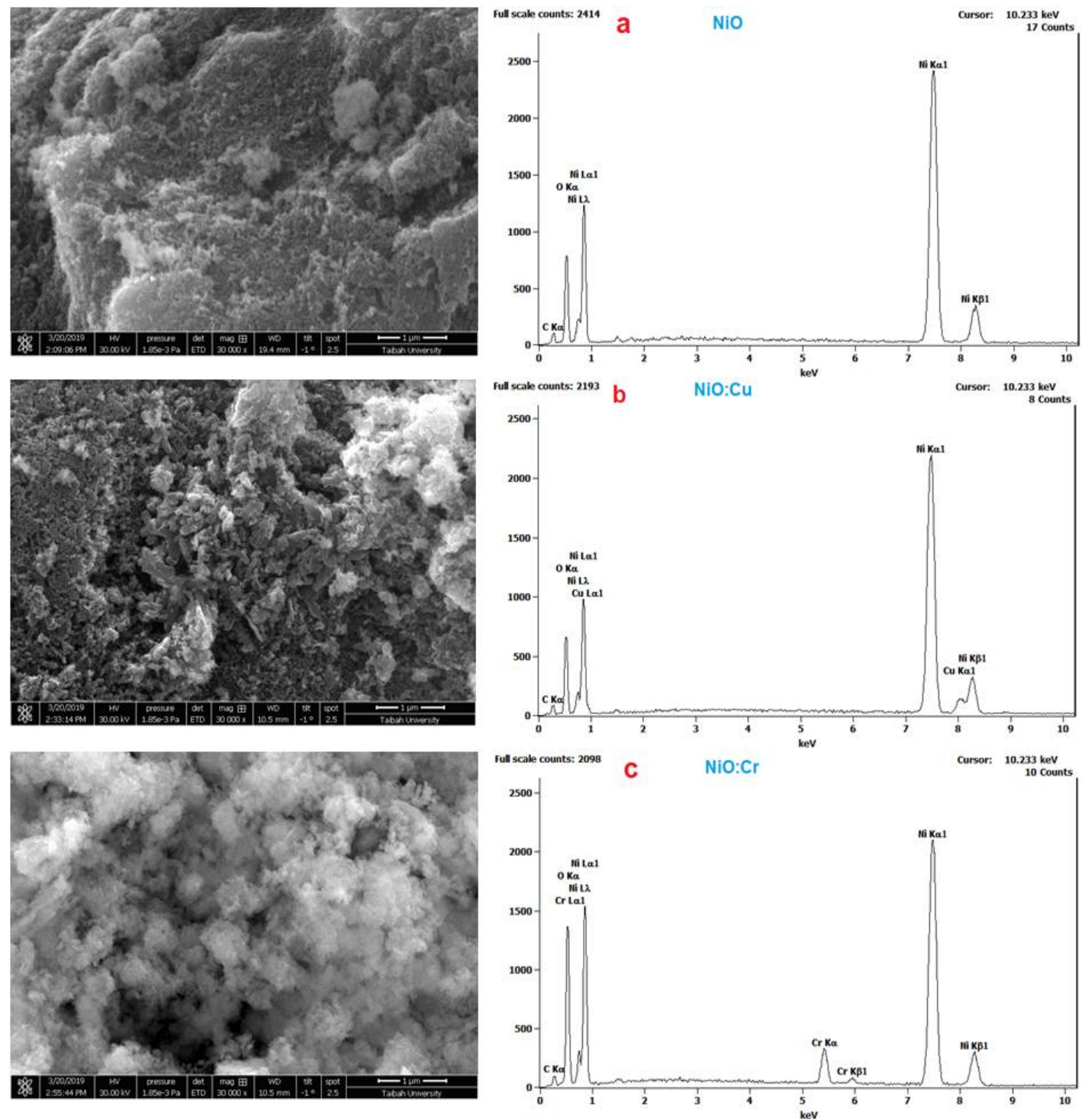

Figure 2: SEM micrographs (left) and EDS spectra (right) of the (a) pure NiO NPs (b) $\mathrm{NiO}: \mathrm{Cu}$ NPs and (c) NiO:Cr NPs prepared at $400^{\circ} \mathrm{C}$ in air. 
TEM micrographs of the prepared NiO NPs are shown in Figure 3. Low magnification (left) showed small submicron-sized agglomerates of the particles presenting voids within the agglomerates.

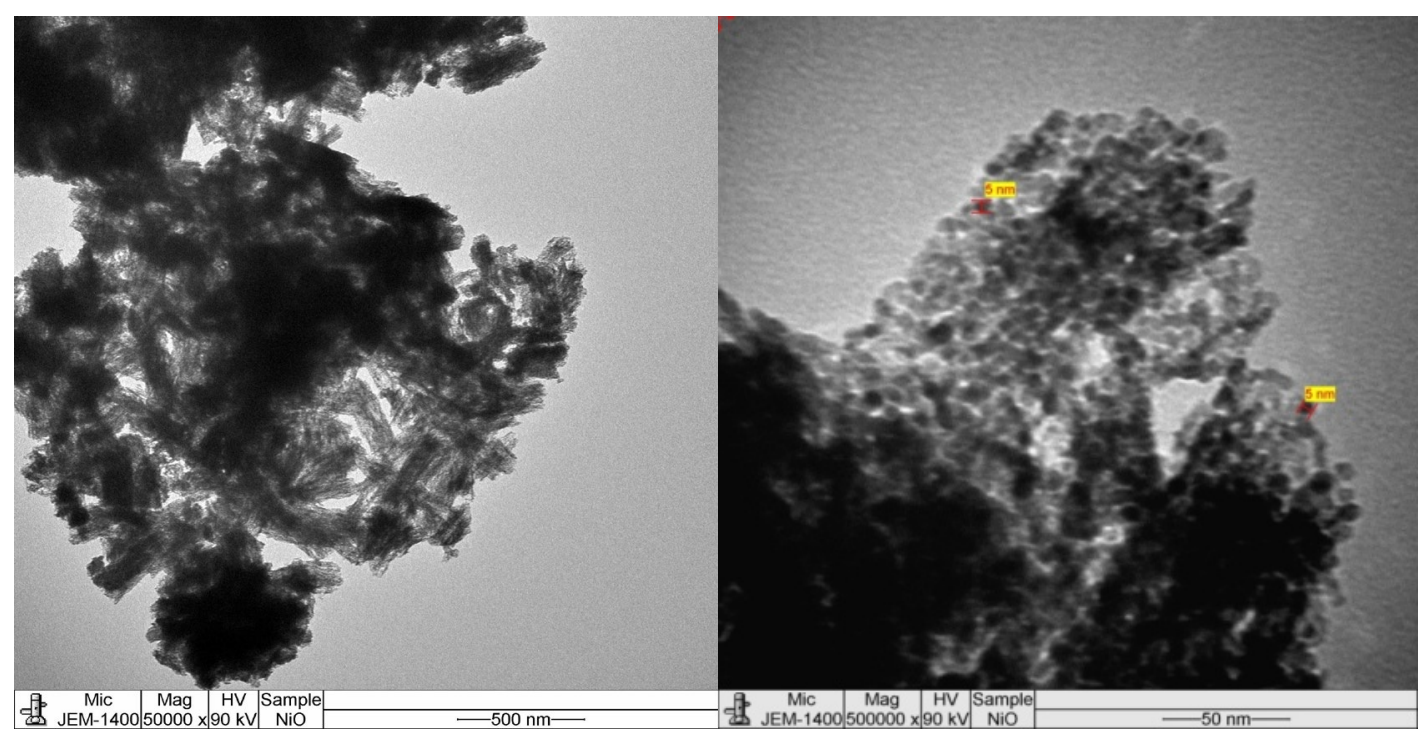

Figure 3: TEM micrographs of the pure $\mathrm{NiO}$ NPs prepared at $400^{\circ} \mathrm{C}$ in air.

The high magnification micrograph (right) reveals very small spherical grain size of about 5-6 nm. The NiO NPs are assembled side by side and aligned along the same direction to form small array shaped nano-agglomerates of about $500 \mathrm{~nm}$ in length and $50-70 \mathrm{~nm}$ in diameter.

\subsection{3 $\mathrm{N}_{2}$ Adsorption Desorption Studies}

Nitrogen adsorption-desorption isotherms permit to get additional information about the microstructure of the prepared materials (Figure 4). NiO NPs represent type IV isotherms with a hysteresis loop at high relative pressure between 0.5 and 1.0, indicating the presence of mesopores $(2-50 \mathrm{~nm})$ and macropores $(>50 \mathrm{~nm})$. The shape of the hysteresis loop was of $\mathrm{H}_{2}$ type which is characteristic of solids composed by small spherical particles also inckbottle shaped pores. This result confirms findings observed in the TEM study. 


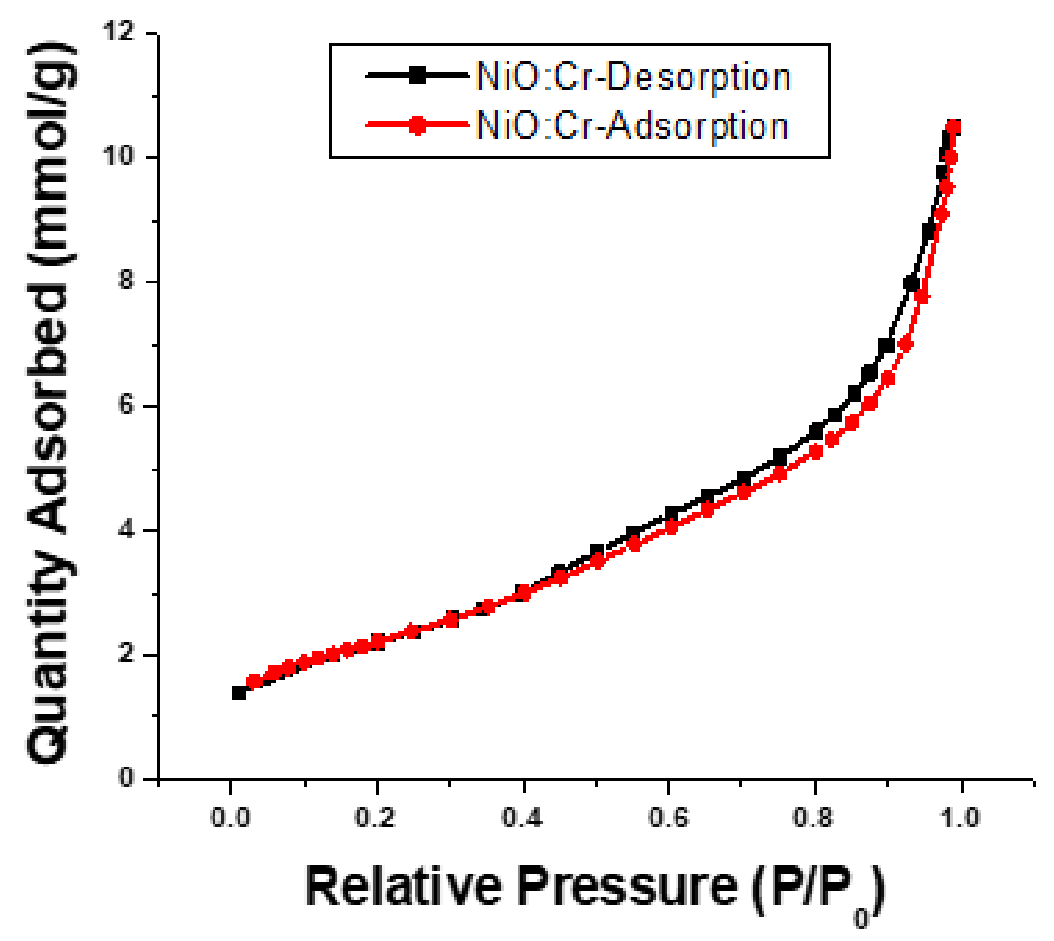

Figure 4: $\mathrm{N}_{2}$ adsorption-desorption isotherms of $\mathrm{NiO}: \mathrm{Cr}$ prepared at $400^{\circ} \mathrm{C}$ in air.

The particle size was also calculated using the specific surface area values obtained from the adsorption-desorption isotherms and compared to those obtained from XRD patterns and assembled in Table 1 where they are given micro-structural information too. There is a good homogeneity in the results of the particles size. The values of DBET used to be higher than those of DXRD due to the agglomeration, the particles are stacked together, thus the adsorption of $\mathrm{N}_{2}$ is decreased. For less agglomerated particles, specific surface area will be higher and the resulting calculated particles size will be nearer of that found in XRD.

\subsection{Dielectric Permittivity and ac Conductivity}

The dielectric permittivity $\left(\varepsilon^{\prime}\right)$ for pure NiO NPs, NiO:Cu NPs and NiO:Cr NPs versus frequency at altered temperatures is displayed in Figure 5. 


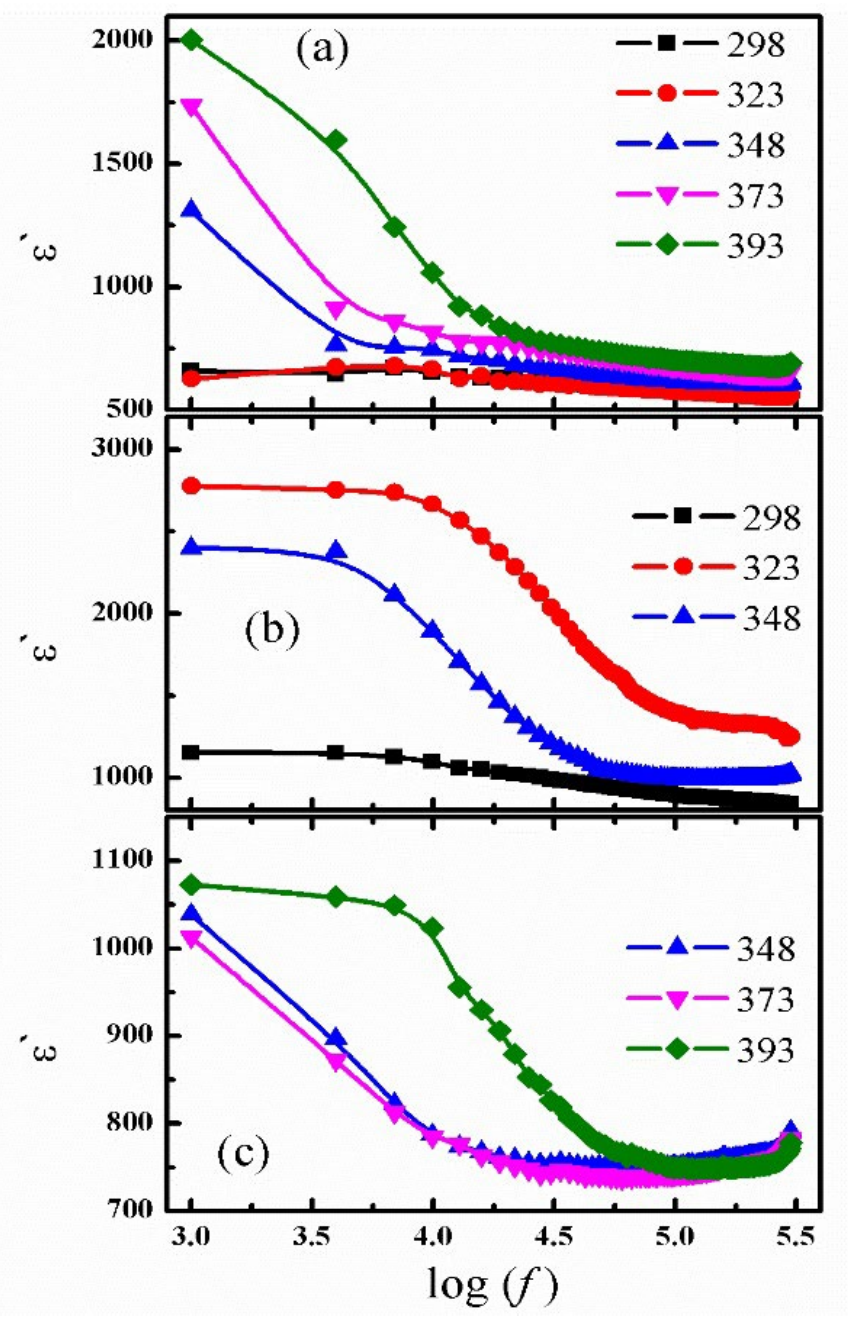

Figure 5: The dielectric constant as a function of temperature for (a) pure NiO NPs (b) NiO:Cr NPs and (c) NiO:Cu NPs.

The value of $\varepsilon^{\prime}$ decreases by increasing frequency, which is ascribed to domain walls reduces, and dipoles can simply orient in the direction of the applied field. The value of $\varepsilon^{\prime}$ increases by the introduction of $\mathrm{Cr}$ ions to $\mathrm{NiO}$ which might attributed to Maxwell - Wegner and space-charge polarization while decreases by the introduction of $\mathrm{Cu}$ ions to $\mathrm{NiO}^{22}$. In addition, the values of $\varepsilon^{\prime}$ increases with temperature for all prepared samples.

The frequency dependence of dielectric modulus $M$ " at different temperatures for pure NiO NPs, NiO:Cr NPs and NiO:Cu NPs were plotted in Figure 6 (a-c). 

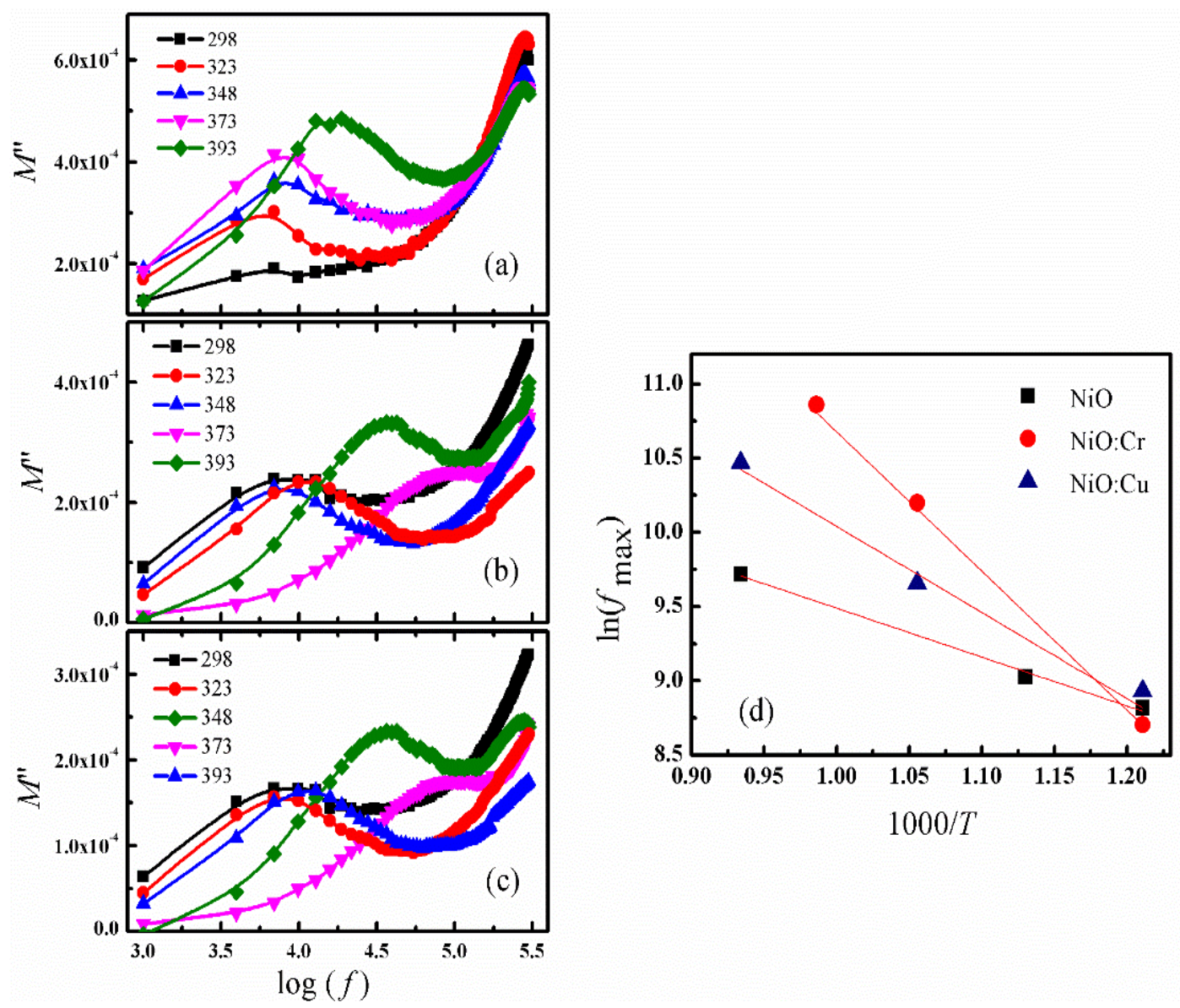

Figure 6: The dielectric modulus, M", temperature for (a) pure NiO NPs (b) NiO:Cr NPs, (c) NiO:Cu NPs and (d) variation of $f_{\max }$ with reciprocal temperature, solid lines shows Arrhenius fit.

Apparently at low frequency relaxation peaks are detected and shifted to higher frequency by increasing the temperature, the shifted peaks can be ascribed to the translation ionic dynamics and the conductivity relaxation of the mobile ions. The maximum peak frequency, $f_{\max }$, for the dielectric modulus as a function of temperature is shown in Figure 6 d. $f_{\max }$ behavior is explained by Arrhenius equation $f_{\max }=$ $f_{o} \exp \left(-E_{r} / k T\right)^{23}$ where $f_{0}$ is a characteristic constant parameter for a particular relaxation process, $k$ is the Boltzmann's constant, and $E_{r}$ is the relaxation energy. The calculated value of $E_{r}$ were about $0.29 \mathrm{eV}, 0.83 \mathrm{eV}$ and $0.51 \mathrm{eV}$ for $\mathrm{NiO}, \mathrm{NiO}: \mathrm{Cr}$ and $\mathrm{NiO}: \mathrm{Cu}$, respectively. The values of Er suggest that the ionic conduction mechanism is suitable for the deliberate sample. 


\subsection{Ac Conductivity $\left(\sigma_{a c}\right)$}

The values of ac conductivity $\left(\sigma_{a c}\right)$ as a function of frequency, can be set by the following equation ${ }^{24}$ :

$\sigma_{a c}=\sigma_{\mathrm{t}}-\sigma_{\mathrm{dc}}=\omega \varepsilon_{0} \varepsilon^{\prime} \tan \delta$

In this expression, $\sigma_{\mathrm{t}}$ is the total conductivity, $\sigma_{\mathrm{dc}}$ is the low-frequency conductivity, $\omega$ is the angular frequency, $\varepsilon_{0}$ is the permittivity of the free space, $\tan \delta$ is loss tangent. Frequency dependence of $\sigma_{\mathrm{ac}}$ for pure NiO NPs, NiO:Cr NPs and NiO:Cu NPs at different fixed temperatures is shown in Figure 7.

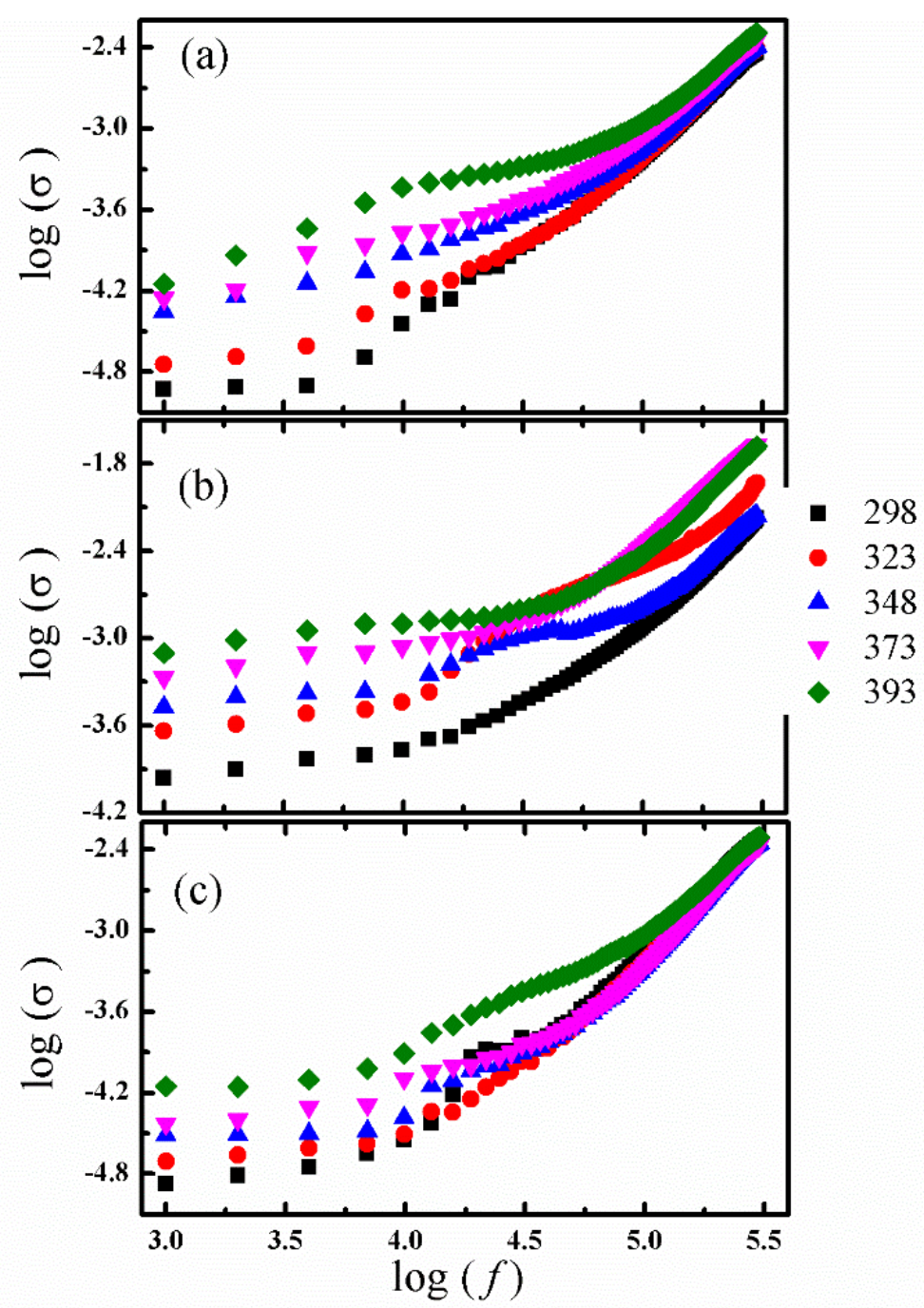

Figure 7. Frequency dependence of $\sigma_{\mathrm{ac}}$ temperature for (a) pure NiO NPs (b) NiO:Cr NPs and (c) NiO:Cu NPs. 
The constant electrical conductivity at low frequency, could be attributed to the dc conductivity. By increasing frequency, the conductivity rises gradually which shows that the charge carriers are transported by hopping via defect sites along the chains. This property is because of the increase of the absorbed energy which consequently results in increasing the number of the charge carriers that contribute to the conduction process. The strong increase of the conductivity observed at high frequencies in an indicator of the power-law dependence of the conductivity on the frequency which may suggest variable range hopping conduction mechanism ${ }^{25}$.

\section{Conclusion}

NiO NPs, NiO:Cu NPs and (c) NiO:Cr NPs were prepared successfully in two steps. X-ray diffraction results showed that all the patterns present the same peaks belonging to the cubic phase of $\mathrm{NiO}$. The peaks broadness increases when doping indicating the decrease of the crystallites size that were estimated by Scherer formula. TEM result showed that the NiO NPs are aligned along the same direction to form arrays of about $500 \mathrm{~nm}$ in length assembled side by side to give small nano-agglomerates of about 50$70 \mathrm{~nm}$ in diameter. $\mathrm{N}_{2}$ adsorption-desorption isotherms showed that NiO NPs is a type IV isotherm with a hysteresis loop at high relative pressure between 0.5 and 1.0, signifying the presence of mesopores $(2-50 \mathrm{~nm})$ and macropores $(>50 \mathrm{~nm})$. The shape of hysteresis loop was of type $\mathrm{H}_{2}$ which is characteristic of inckbottle shaped pores and also solids composed by small spherical particles. The values of $\varepsilon$ ' decrease when increasing the frequency. The values of $\varepsilon$ ' increases by the addition of $\mathrm{Cr}$ ions to $\mathrm{NiO}$ and decreases by the addition of $\mathrm{Cu}$ ions to $\mathrm{NiO}$. A low frequency relaxation peak is observed for pure NiO NPs, NiO:Cr NPs and NiO:Cu NPs and shifted to higher frequency with increasing temperature. The electrical conductivity could be constant at low frequency, which was attributed to the dc conductivity. By increasing frequency, the conductivity also increases steadily which shows that the charge carriers are transported through hopping via defect sites across the chains.

Conflicts of Interest: "The authors declare no conflict of interest." 


\section{$5 \quad$ References}

(1) Eranna, G.; Joshi, B.; Runthala, D.; Gupta, R. Oxide Materials for Development of Integrated Gas Sensors-a Comprehensive Review. Crit. Rev. Solid State Mater. Sci. 2004, 29 (3-4), 111-188.

(2) Ingelrest, F.; Barrenetxea, G.; Schaefer, G.; Vetterli, M.; Couach, O.; Parlange, M. Sensorscope: Application-Specific Sensor Network for Environmental Monitoring. ACM Trans. Sens. Netw. TOSN 2010, 6 (2), 1-32.

(3) Eranna, G.; Joshi, B.; Runthala, D.; Gupta, R. Critical Reviews in Solid State and Materials Sciences. Solid State Mater. Sci. 2004, 29 (3-4), 111-188.

(4) Tripathy, S. K.; Pattanaik, A. Optical and Electronic Properties of Some Semiconductors from Energy Gaps. Opt. Mater. 2016, 53, 123-133.

(5) Yasin, G.; Arif, M.; Mehtab, T.; Shakeel, M.; Khan, M. A.; Khan, W. Q. Metallic Nanocomposite Coatings. In Corrosion Protection at the Nanoscale; Elsevier, 2020; pp 245-274.

(6) Choi, H. C.; Jung, Y. M.; Kim, S. B. Size Effects in the Raman Spectra of TiO2 Nanoparticles. Vib. Spectrosc. 2005, 37 (1), 33-38.

(7) Monticone, S.; Tufeu, R.; Kanaev, A.; Scolan, E.; Sanchez, C. Quantum Size Effect in TiO2 Nanoparticles: Does It Exist? Appl. Surf. Sci. 2000, 162, 565570.

(8) Oskam, G. Metal Oxide Nanoparticles: Synthesis, Characterization and Application. J. Sol-Gel Sci. Technol. 2006, 37 (3), 161-164.

(9) Kodama, R. H.; Makhlouf, S. A.; Berkowitz, A. E. Finite Size Effects in Antiferromagnetic NiO Nanoparticles. Phys. Rev. Lett. 1997, 79 (7), 1393.

(10) Winkler, E.; Zysler, R.; Mansilla, M. V.; Fiorani, D. Surface Anisotropy Effects in NiO Nanoparticles. Phys. Rev. B 2005, 72 (13), 132409.

(11) Wang, N.; Song, H.; Ren, H.; Chen, J.; Yao, M.; Huang, W.; Hu, W.; Komarneni, S. Partly Nitrogenized Nickel Oxide Hollow Spheres with Multiple Compositions for Remarkable Electrochemical Performance. Chem. Eng. J. 2019, 358, 531-539.

(12) Abzieher, T.; Moghadamzadeh, S.; Schackmar, F.; Eggers, H.; Sutterlüti, F.; Farooq, A.; Kojda, D.; Habicht, K.; Schmager, R.; Mertens, A. Electron-beamevaporated Nickel Oxide Hole Transport Layers for Perovskite-based Photovoltaics. Adv. Energy Mater. 2019, 9 (12), 1802995.

(13) Wang, J.; Cai, J.; Lin, Y.-H.; Nan, C.-W. Room-Temperature Ferromagnetism Observed in Fe-Doped NiO. Appl. Phys. Lett. 2005, 87 (20), 202501.

(14) Gleiter, H. Nanostructured Materials: Basic Concepts and Microstructure. Acta Mater. 2000, 48 (1), 1-29.

(15) Biju, V.; Khadar, M. A. AC Conductivity of Nanostructured Nickel Oxide. $J$. Mater. Sci. 2001, 36 (24), 5779-5787.

(16) Basri, N.; Deraman, M.; Daik, R.; Ayob, M. T. M.; Sahri, M. I.; Nor, N.; Dolah, B.; Soltaninejad, S. Electrochemical Impedance Spectroscopy Study of Supercapacitors Using Deposited Nickel Oxide Nanoparticles Carbon Monolith Electrodes; Trans Tech Publ, 2015; Vol. 1112, pp 236-240.

(17) Sheena, P. A. L.; Sreedevi, A.; Viji, C.; Thomas, V. Nickel Oxide/Cobalt Phthalocyanine Nanocomposite for Potential Electronics Applications. Eur. Phys. J. B 2019, 92 (1), 1-8.

(18) Avendaño, E.; Azens, A.; Niklasson, G.; Granqvist, C. Electrochromism in Nickel Oxide Films Containing Mg, Al, Si, V, Zr, Nb, Ag, or Ta. Sol. Energy Mater. Sol. Cells 2004, 84 (1-4), 337-350. 
(19) Manouchehri, I.; Mehrparvar, D.; Moradian, R.; Gholami, K.; Osati, T. Investigation of Structural and Optical Properties of Copper Doped NiO Thin Films Deposited by RF Magnetron Reactive Sputtering. Optik 2016, 127 (19), 8124-8129.

(20) Leinfelder, K. F. An Evaluation of Casting Alloys Used for Restorative Procedures. J. Am. Dent. Assoc. 1997, 128 (1), 37-45.

(21) Benatti, O. F.; Miranda Jr, W. G.; Muench, A. In Vitro and in Vivo Corrosion Evaluation of Nickel-Chromium-and Copper-Aluminum-Based Alloys. $J$. Prosthet. Dent. 2000, 84 (3), 360-363.

(22) Srinivasan, M.; Punithavelan, N. Structural, Morphological and Dielectric Investigations on $\mathrm{NiO} / \mathrm{CuO} / \mathrm{ZnO}$ Combined Semiconductor Metal Oxide Structures Based Ternary Nanocomposites. Mater. Res. Express 2018, 5 (7), 075033.

(23) Rehwald, W.; Kiess, H.; Binggeli, B. Frequency Dependent Conductivity in Polymers and Other Disordered Materials. Z. Für Phys. B Condens. Matter 1987, 68 (2), 143-148.

(24) Abdel-Baset, T.; Bashal, A. H. Structure and AC Conductivity of Zinc and Nickel-Doped TiO 2 Nanocomposite Synthesized by Simple Incipient Wet Impregnation Method. J. Mater. Sci. Mater. Electron. 2020, 31 (21), 1853318540.

(25) Abou Elfadl, A.; Ismail, A.; Mohammed, M. Dielectric Study and AC Conduction Mechanism of Gamma Irradiated Nano-composite of Polyvinyl Alcohol Matrix with Cd 0.9 Mn 0.1 S. J. Mater. Sci. Mater. Electron. 2020, 31 (11), 8297-8307. 
Figures

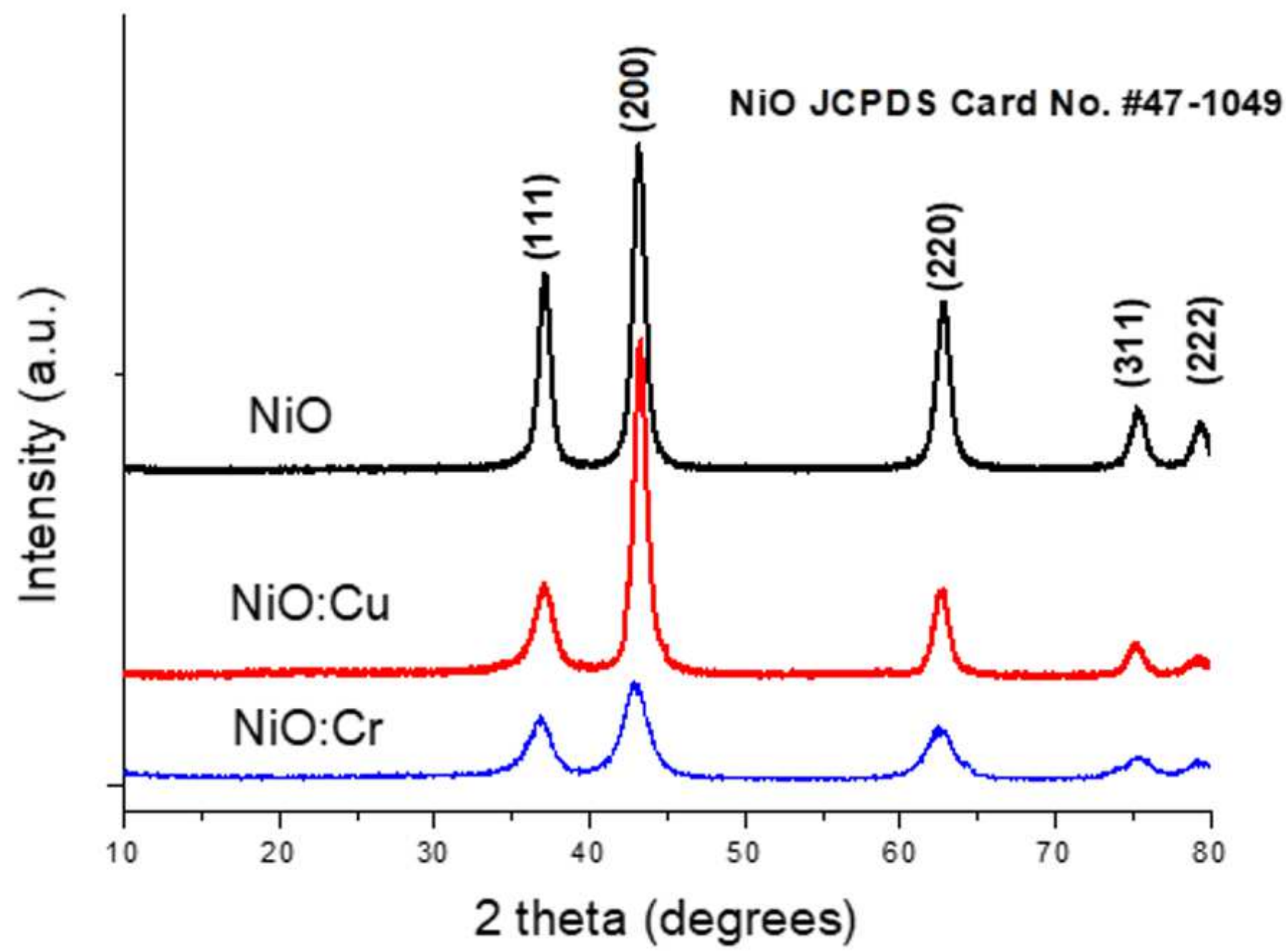

Figure 1

Compared XRD patterns of NiO NPs pure and 10\% molar doped with copper or chromium $\mathrm{NiO}: \mathrm{Cu}$ and $\mathrm{NiO}: \mathrm{Cr}$ prepared at $400^{\circ} \mathrm{C}$ in air. 

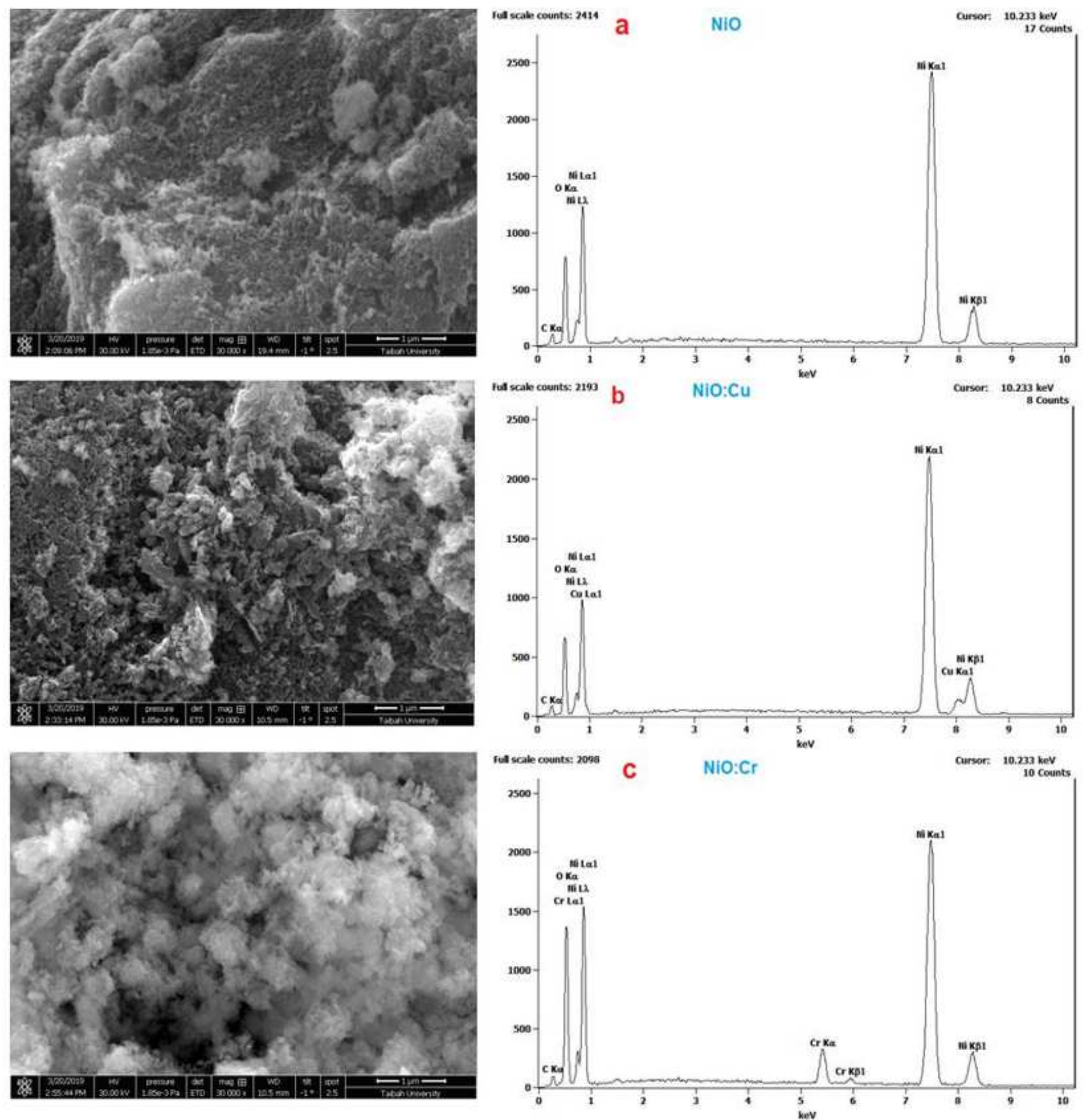

Figure 2

SEM micrographs (left) and EDS spectra (right) of the (a) pure NiO NPs (b) NiO:Cu NPs and (c) NiO:Cr NPs prepared at $400^{\circ} \mathrm{C}$ in air. 


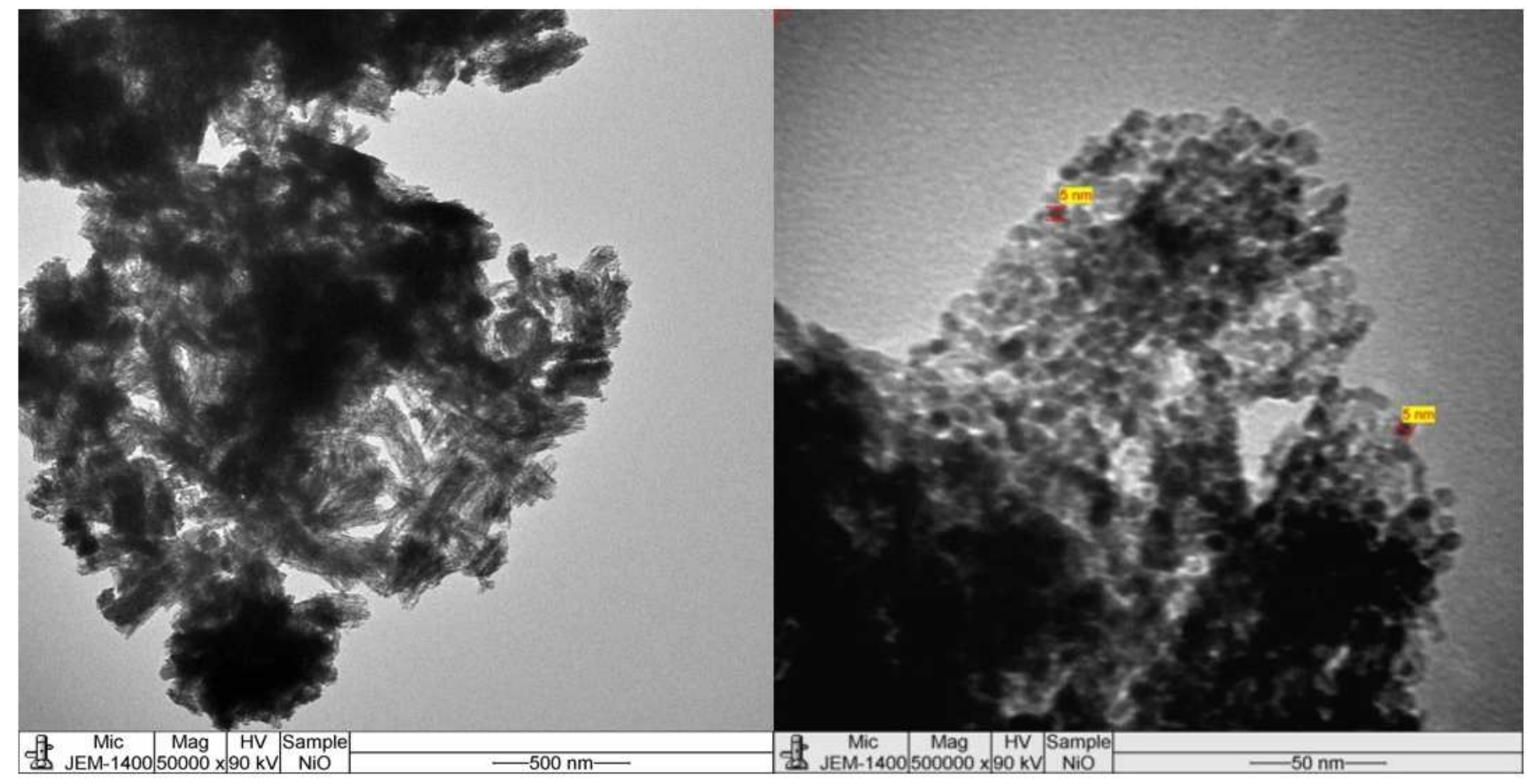

Figure 3

TEM micrographs of the pure NiO NPs prepared at $400^{\circ} \mathrm{C}$ in air. 


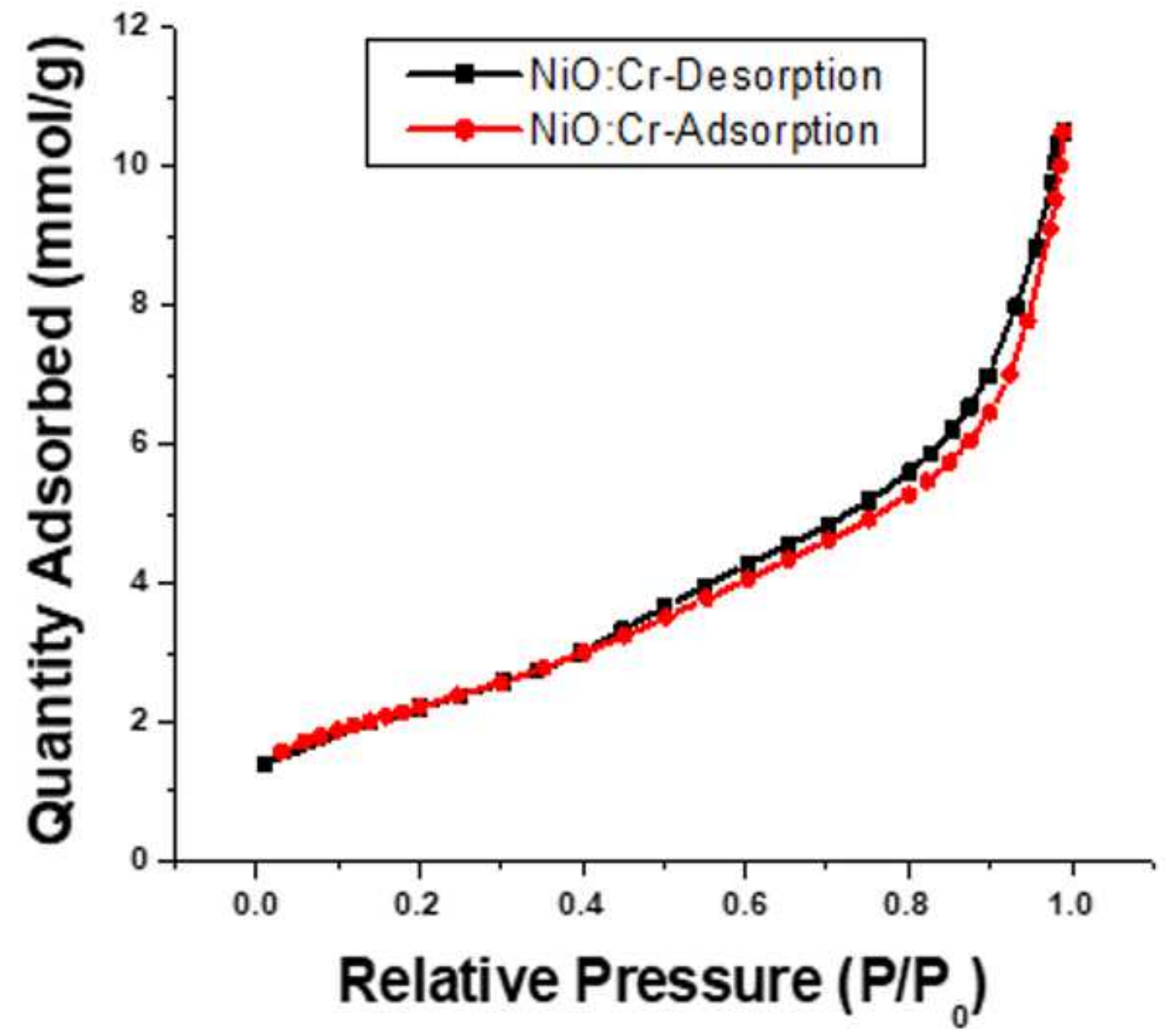

Figure 4

$\mathrm{N} 2$ adsorption-desorption isotherms of $\mathrm{NiO}: \mathrm{Cr}$ prepared at $400^{\circ} \mathrm{C}$ in air. 


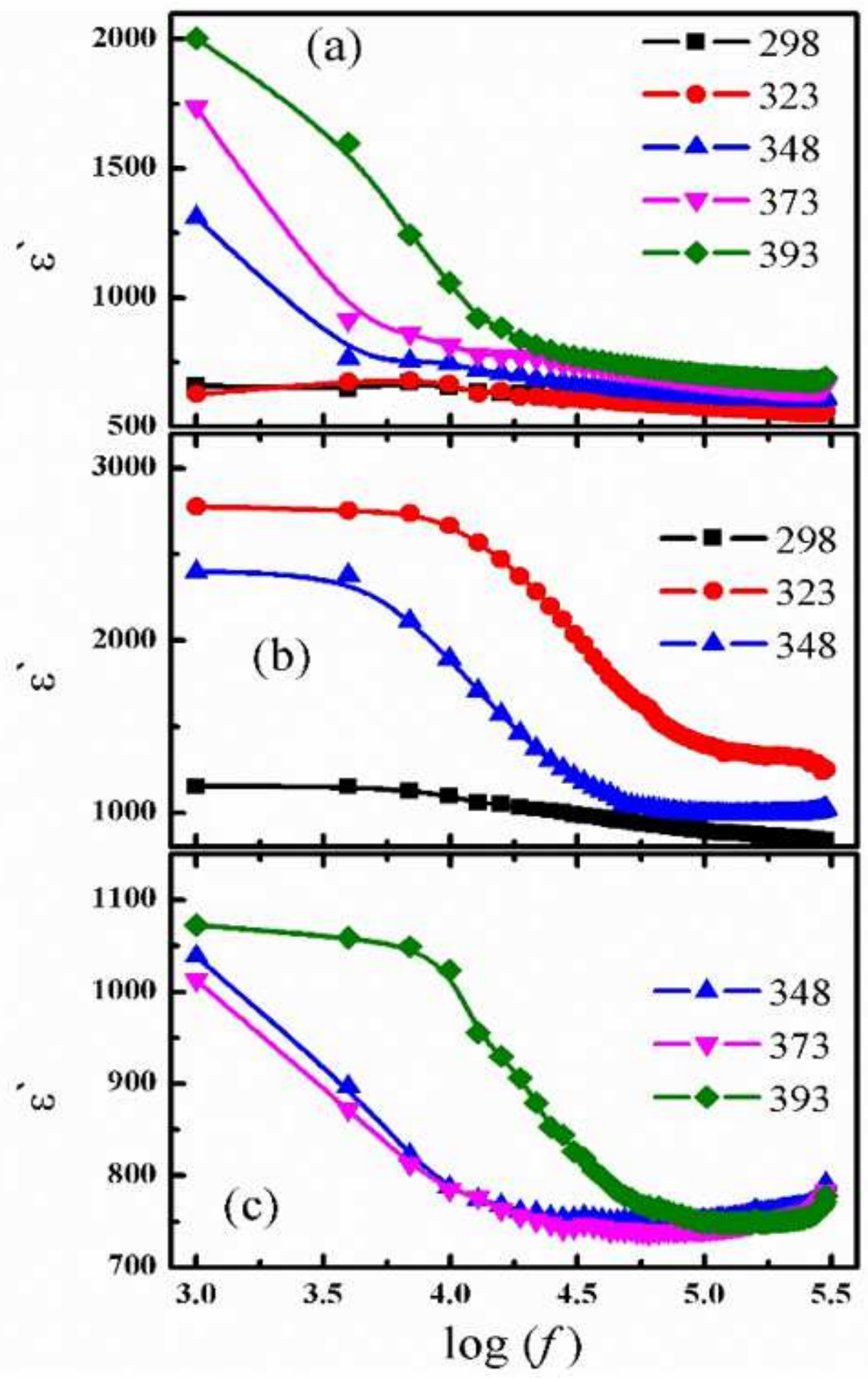

Figure 5

The dielectric constant as a function of temperature for (a) pure NiO NPs (b) NiO:Cr NPs and (c) NiO:Cu NPs. 


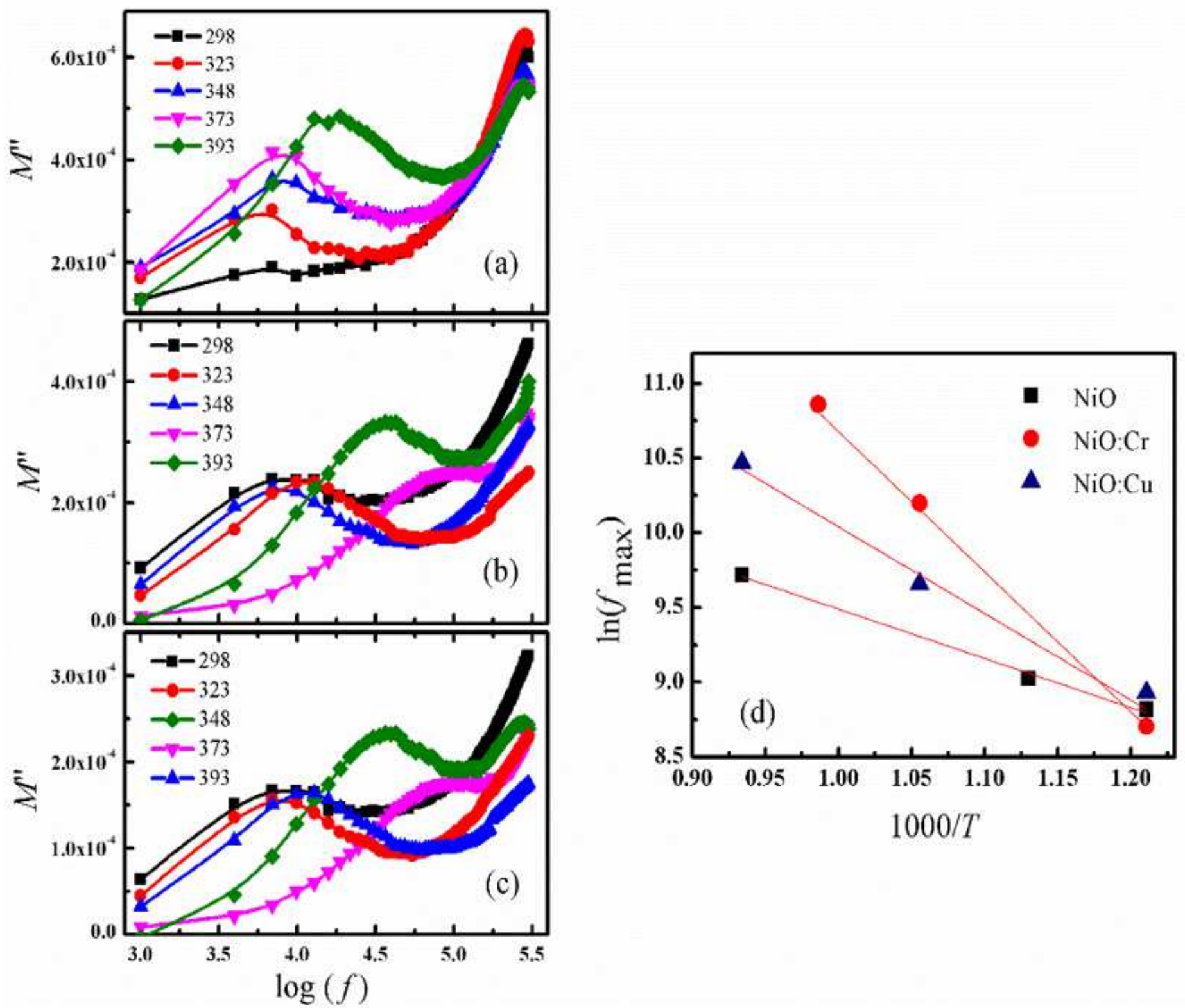

Figure 6

The dielectric modulus, M", temperature for (a) pure NiO NPs (b) NiO:Cr NPs, (c) NiO:Cu NPs and (d) variation of fmax with reciprocal temperature, solid lines shows Arrhenius fit. 


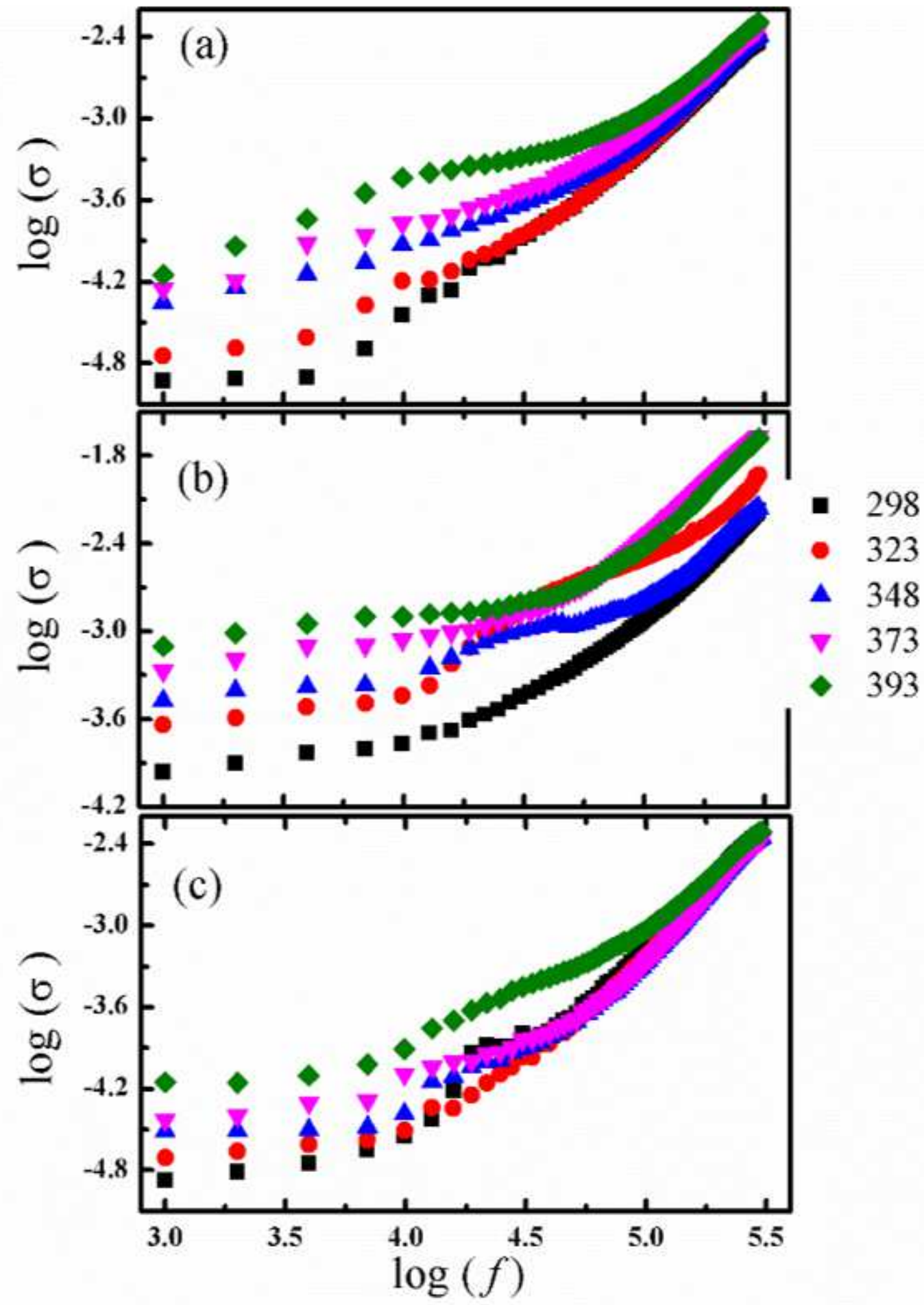

Figure 7

Frequency dependence of oac temperature for (a) pure NiO NPs (b) NiO:Cr NPs and (c) NiO:Cu NPs. 